\title{
Optimising outcomes in the management of spontaneous cerebrospinal fluid rhinorrhoea*
}

\author{
Jagdeep Singh Virk, Behrad Elmiyeh, Constantine Stamatoglou, \\ Hesham A. Saleh \\ Rhinology 51: 0-0, 2013 \\ DOI:10.4193/Rhino13.008 \\ *Received for publication: \\ February 8, 2013 \\ Otolaryngology Department, Charing Cross Hospital, Imperial College Healthcare, London, United Kingdom \\ Accepted: March 10, 2013
}

\section{Summary}

Background: To describe our experience of the management of spontaneous cerebrospinal fluid (CSF) rhinorrhoea in a large case series focusing on surgical approach, peri-operative management and outcomes; to evaluate the efficacy of endoscopic CSF leak repairs.

Methodology: Retrospective chart review was performed for all patients with spontaneous CSF rhinorrhoea managed from 2003 to 2011 at a tertiary referral centre. Data regarding demographics, presentation, site of leak, peri-operative management, surgical approach, body mass index (BMI), follow up and success rates was collated.

Results: Thirty-six patients were identified: 9 male and 27 female with a mean age of 50.4 years. Eight patients had previous failed repairs in other units. Success rate after first surgery was $89 \%$ and after second surgery was $100 \%$. Four patients had recurrences, 3 underwent successful revisions and the fourth had complete cessation of the leak after gastric bypass surgery and weight reduction. All failures were before 2004 prior to instigation of an anatomic three-layered repair with no further failures in the following 7 years. Mean follow up was 21.5 months. Mean body mass index was $34.0 \mathrm{~kg} / \mathrm{m}^{2}$. Fifty percent of spontaneous leaks were from the cribriform plate, $22 \%$ sphenoid, $14 \%$ ethmoid and $14 \%$ frontal sinus.

Conclusion: Endoscopic CSF fistula closure has become the gold standard of care. In order to optimise the outcome, we recommend a multidisciplinary approach to manage the associated idiopathic intracranial hypertension and an anatomic three-layered closure technique for recalcitrant cases.

Key words: cerebrospinal fluid, rhinorrhoea, spontaneous, endoscopic, skull base

\section{Introduction}

Spontaneous cerebrospinal fluid (CSF) rhinorrhoea is an idiopathic CSF leakage where no definable cause such as tumour, trauma or previous surgery is present ${ }^{(1,2)}$. Recent studies have associated spontaneous CSF leaks with raised intracranial pressure (ICP) and an underlying diagnosis of idiopathic intracranial hypertension $(\mathrm{IIH})^{(3-6)}$. The primary disorder of spontaneous leaks is that of CSF circulation, manifesting itself via a dehiscence of the skull base.
Spontaneous CSF rhinorrhoea classically presents with unilateral intermittent clear watery nasal discharge affected by posture and valsalva manoeuvres. Patients with IIH may present with headache, tinnitus, imbalance, visual disturbance alongside radiographic findings of a total or partial empty sella ${ }^{(2)}$. Both IIH and spontaneous CSF rhinorrhoea occur more commonly in obese middle-aged females ${ }^{(6)}$.

Endoscopic CSF leak repair aims to produce a complete and robust separation of the subarachnoid space from the nasal 
cavity hence minimising the risk of intracranial infections from the sinonasal cavity which can approach $20 \%$ if untreated ${ }^{(7)}$. In addition, this restores normal CSF circulation which is critical in maintaining brain buoyancy and preventing CSF hypotension ${ }^{(8)}$. Endoscopic closure of CSF fistulae is now recognised as the gold standard of management with high success rates (Table 1) ${ }^{(9-11)}$. Spontaneous CSF rhinorrhoea is the most difficult aetiological subgroup, less likely to achieve a successful closure, with reported failure rates of $25-87 \%$ in the 1970 s and less than $10 \%$ in more recent series ${ }^{(9,12-15)}$.

Despite several published articles including a recent systematic review on the endoscopic repair of CSF leaks many questions remain unanswered regarding the management of the recalcitrant cases with spontaneous leak aetiology ${ }^{(16)}$. This study evaluates the management and outcomes of spontaneous CSF rhinorrhoea at a tertiary referral centre over an eight year period.

\section{Materials and methods}

\section{Study population}

A cohort of 36 patients, attending for management of spontaneous CSF rhinorrhoea from 2003 to 2011, was identified from the senior author's prospectively maintained patient database ${ }^{(17)}$. The minimum data set collected for each case incorporated patient demographics; presentation; site of leak; body mass index (BMI); evidence of raised intracranial pressure (ICP); perioperative management; operative technique; outcome; length of follow up alongside complications.

The London Research Ethics Committee confirmed that ethical approval was not required for the study.

\section{Peri-operative and surgical management}

Pre-operatively, nasal secretions were tested for $\beta 2$ transferrin to confirm CSF leak and $1 \mathrm{~mm}$ thickness high resolution computed tomography $(\mathrm{CT})$ of paranasal sinuses, using BrainLabR (BrainLAB, Heimstetten, Germany) protocol was performed to allow intraoperative navigation. Magnetic resonance imaging (MRI) was performed when there was suspicion of a meningoencephalocele or the site of leak was not identified on CT.

All patients underwent a formal neurological review for assessment and management of any underlying primary pathology resulting in CSF rhinorrhoea.

An endoscopic approach was used in all patients by the senior author (HAS). Intrathecal fluorescein was utilised intra-operatively to delineate skull base defects in all revision cases, in those with potential multiple leak sites and if imaging failed to clarify an anatomical defect. Of note, this is an off-label indication for intrathecal fluorescein and as such, should be used with caution with fully informed consent.

A day prior to surgery, all patients underwent skin prick testing with fluorescein eye drops to rule out significant adverse reaction ${ }^{(18)}$. On the day of surgery, intramuscular chlorpheniramine was injected prior to intrathecal injection of sterile and filtered fluorescein similar to Lund's protocol ${ }^{(18)}$. However we did not routinely lie the patient head down in recovery postinjection for one hour because, in our experience, the elapsed time between the injection and starting the surgery was usually sufficient for the spread of fluorescein. Only if no dye was seen intraoperatively, a head down tilt and valsalva manoeuvre was performed.

Following nasal decongestion with Moffet's solution, appropriate endoscopic sinus dissection was performed to gain sufficient exposure to the site of the leak. Lateral lamella or ethmoid sinus leaks were accessed with an ethmoidectomy, olfactory groove leaks with a partial middle turbinectomy and frontal sinus leaks with a modified Lothrop/Draf III approach ${ }^{(19)}$. Sphenoid sinus leak sites did not typically require disturbance of other sinuses. Complete fronto-spheno-ethmoidectomy was performed if the defect was not pre-operatively identified on imaging and the skull base inspected carefully to delineate the fistula with the help of intrathecal fluorescein.

Reduction of herniated mucosa or diathermy of an encephalocele was performed if present ${ }^{(20)}$. The mucosal perimeter of the leak site was denuded by up to $5 \mathrm{~mm}$ if possible.

Prior to 2004, all defects were repaired with a two layered approach, commonly with fascia lata and nasal mucosa. From 2004 onwards, the defects $<4 \mathrm{~mm}$ were continued to be repaired with the original 2 layered technique, however we adopted an anatomic three layered repair for the defects $\geq 4 \mathrm{~mm}^{(17,21)}$. The choice of graft material used varied according to the size and the site of the leak and included fascia lata or duragen ${ }^{\circledast}$, septal cartilage, bone pate, fat and middle turbinate mucosa ${ }^{(21)}$. In ethmoid and olfactory defects a fascia lata underlay followed by septal cartilage and free turbinate mucosa was used. Sphenoid defects were commonly repaired using fascia lata followed by fat obliteration after denuding the mucosa to avoid possible mucocele formation. In two revision sphenoid cases bone pate harvested from mastoid bone was successfully placed between fascia lata and turbinate mucosa. Frontal recess repair technique was similar to those with ethmoid and olfactory defects. However, most of these defects were $<4 \mathrm{~mm}$ and as such only required a two layered closure. Fat grafting in the frontal region was avoided as obstructing the frontal recess has a potential risk of sinusitis and mucocele formation ${ }^{(17)}$. In 2 cases where fascia lata was unavailable, Duragen ${ }^{\circledR}$ (Integra ${ }^{\mathrm{TM}}$, Plainsboro, $\mathrm{NJ}, \mathrm{USA}$ ) was incorporated. A watertight seal was achieved in all cases by applying fibrin sealant Tisseel ${ }^{\circledast}$ (Baxter Corporation, Deerfield, IL, USA) between the first and second layers and superficial to the third layer of the repair ${ }^{(22)}$.

Lumbar drains were utilised in those with raised intracranial pressure, all revision cases and those with defects $\geq 4 \mathrm{~mm}$ in 


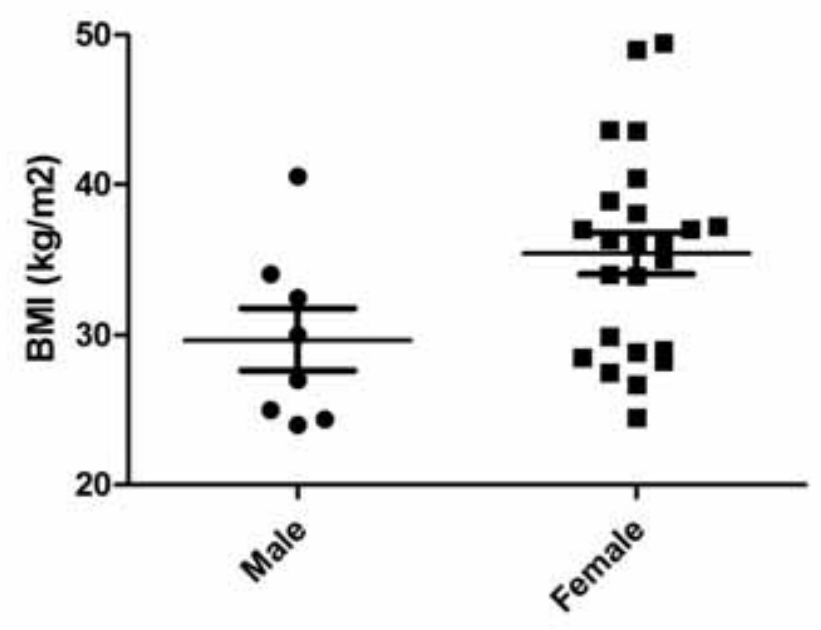

Figure 1. Comparison of BMI by gender.

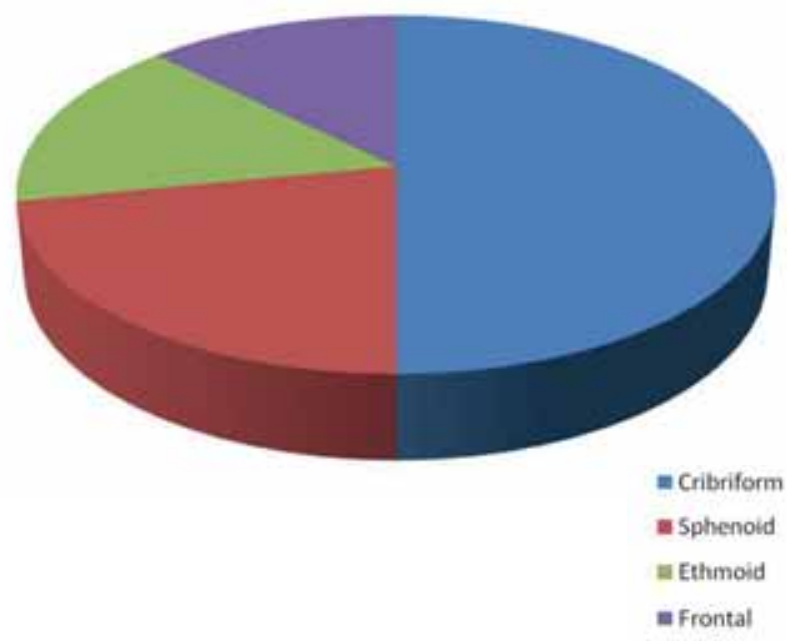

Figure 2. Site of anatomical defect. size. Also intra-operatively, if the leak was under high pressure, 10 to $20 \mathrm{ml} \mathrm{CSF}$ was removed to facilitate a watertight repair, alongside the use of a lumbar drain ${ }^{(17)}$.

Post-operatively, patients maintained strict bed rest for 48-72 hours with the head elevated 30 degrees. All efforts were made to prevent an increase in intra-cranial pressure incorporating the use of laxatives, avoidance of straining and nose blowing. In earlier cases, Whitehead's varnish impregnated gauze nasal packing was inserted and removed in one week under general anaesthesia. Since 2009, Nasopore ${ }^{\circledR}$ (Polyganics, Groningen, the Netherlands), a biodegradable nasal pack was used obviating the need for a second anaesthetic for pack removal. Prophylactic co-amoxiclav antibiotic was dispensed for a one week period.

\section{Statistical analysis}

Statistical analysis was performed using GraphPad PrismR v5.0 (GraphPad ${ }^{\circledR}$ Software Inc., La Jolla, CA, USA).

\section{Results}

\section{Demographics}

Thirty six patients were identified, of which 9 were male (25\%) and 27 female (75\%). Mean age was 50.4 years. There was no statistically significant difference $(p>0.30)$ between the mean age of the male and female patients. Eight patients (22\%) were revision cases all of whom had their initial surgeries in other units.

\section{Presentation}

The mean duration of CSF rhinorrhoea prior to presentation was 14.5 months ( $95 \% \mathrm{Cl}$ : 9.8 to 19.1 months).

Eight patients (22.2\%) had episodes of meningitis pre-operatively, with 2 having 3 incidents, 3 having 2 attacks and 3 having one.

The mean BMl in all patients was $34.0 \mathrm{~kg} / \mathrm{m}^{2}$. There was a statis- tically significant higher BMI in the female group $\left(35.4 \mathrm{~kg} / \mathrm{m}^{2}\right)$ compared to the male group $\left(29.7 \mathrm{~kg} / \mathrm{m}^{2}\right),(p<0.05)$ (Figure 1).

\section{Size and site of leak}

Size of the defects ranged from less than $1 \mathrm{~mm}$ to $30 \mathrm{~mm}$. Mean defect size was $10.6 \mathrm{~mm}$ ( $95 \% \mathrm{Cl}: 5.6$ - 15.6).

The anatomical defects were in the cribriform plate in 18 patients (50\%), sphenoid bone in $8(22 \%)$ and ethmoid bone as well as frontal recess in 5 (14\%) each (Figure 2).

\section{Peri-operative measures}

Nasal secretion sample for Beta 2 transferrin yielded positive in 33 patients (92\%).

Intra-operative intrathecal fluorescein was utilized in 33 patients (92\%), identifying skull base defects in all but one patient (97\%) but a $1 \mathrm{~mm}$ defect was noted anatomically in the ethmoid roof. There were no adverse reactions to the fluorescein skin prick tests and its intrathecal injection.

A lumbar drain was used in 22 patients (61\%) with no documented side effects

\section{Surgical outcomes and follow up}

After our first surgery, success rate was $89 \%$ (32/36) followed by $100 \%$ success for our second operative intervention on 3 of our 4 failed cases. The 4th patient declined to undergo further revision surgery and will be discussed in the next paragraph. There were 8 patients referred from other units who had undergone at least one attempted surgical repair elsewhere. The CSF leak in 7 of these 8 patients resolved following our first surgical repair. Our surgical attempt failed in one lady with BMI of 43.6 $\mathrm{kg} / \mathrm{m}^{2}$ who had also undergone two previous failed surgeries. She declined further revision surgery and was referred to have gastric bypass surgery with subsequent complete cessation of leak to date (18 months). This lady was one of our total 4 
Table 1. Review of literature of endoscopic fistula closure.

\begin{tabular}{|c|c|c|c|c|c|c|c|}
\hline \multirow{2}{*}{$\begin{array}{l}\text { First author } \\
\text { Lund }{ }^{(18)}\end{array}$} & \multirow{2}{*}{$\begin{array}{l}\text { Year } \\
2002\end{array}$} & \multirow{2}{*}{$\begin{array}{c}\text { Number of } \\
\text { patients } \\
12\end{array}$} & \multirow{2}{*}{$\begin{array}{c}\begin{array}{c}\text { Duration } \\
\text { (years) }\end{array} \\
7\end{array}$} & \multicolumn{2}{|c|}{$\begin{array}{l}\text { Success Rate } \\
\text { (1st, 2nd) (\%) }\end{array}$} & \multirow{2}{*}{$\begin{array}{c}\text { Follow up } \\
\text { (months) }\end{array}$} & \multirow{2}{*}{ 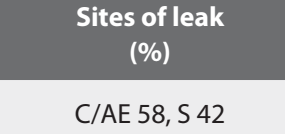 } \\
\hline & & & & 75.0 & $?$ & & \\
\hline Schlosser ${ }^{(42)}$ & 2003 & 16 & 6 & 100.0 & - & Mean: 14.1 & S 55, E 27, C 9, F 9 \\
\hline Lopatin $^{(13)}$ & 2003 & 21 & 3 & 95.2 & $?$ & Range: 9 - 42 & S 43, C 29, E 29 \\
\hline McMains ${ }^{(43)}$ & 2004 & 19 & 12 & $? 85.0$ & 92 & Mean: 25 & S 58, C 42 \\
\hline Lindstrom ${ }^{(11)}$ & 2004 & 13 & 10 & 84.6 & & Mean: 58.8 & C 46, S 31, E 7, F 15 \\
\hline Mirza ${ }^{(44)}$ & 2006 & 29 & 10 & 79.3 & $? 93$ & Mean: 60 & ${ }^{*} \mathrm{~S} 31, \mathrm{C} 27, \mathrm{E} 21, \mathrm{~F} 19$ \\
\hline Woodworth ${ }^{(15)}$ & 2008 & 56 & 10 & 89.0 & $?$ & Mean: 34 & S 45, E 26, C 18, F 11 \\
\hline Presutti (45) & 2009 & 13 & 17 & 84.6 & 100 & Mean: 47 & AE 61, S 15, PE 23 \\
\hline Banks ${ }^{(9)}$ & 2009 & 77 & 21 & 91.0 & ${ }^{* 98}$ & Mean: 21 & S 40, E 27, C 21, F 12 \\
\hline Cassano ${ }^{(46)}$ & 2009 & 43 & 10 & 83.7 & 100 & Mean: 96.6 & ${ }^{*} \mathrm{~S} 34, \mathrm{C} 34, \mathrm{AE} 17, \mathrm{PE} 14$ \\
\hline Seth ${ }^{(2)}$ & 2010 & 39 & 10 & 87.1 & 100 & Mean: 33.6 & C 51, S 31, E 8 \\
\hline Gilat ${ }^{(26)}$ & 2011 & 7 & 10 & 100.0 & - & Mean: 24 & C 100 \\
\hline \$Psaltis ${ }^{(16)}$ & 2012 & 1778 & - & ${ }^{*} 90.6$ & ${ }^{*} 96.6$ & Mean: 35.9 & ${ }^{*} \mathrm{C} / \mathrm{E} 53, \mathrm{~S} 30, \mathrm{~F} 7$ \\
\hline & & 345 & Mean: 10.5 & Mean: $\mathbf{8 7 . 9}$ & lean: 97.2 & $\begin{array}{l}\text { Estimated Mean: } \\
39.3 \text { C/AE 58, }\end{array}$ & $\begin{array}{c}\text { Means: } \\
35 \mathrm{~S}, 34 \mathrm{C}, 24 \mathrm{E}, 6 \mathrm{~F}\end{array}$ \\
\hline
\end{tabular}

*overall percentage, not only for spontaneous aetiology. ${ }^{5}$ systematic review, not included in calculations.

$\mathrm{S}=$ Sphenoid $\mathrm{C}=$ Cribriform, $\mathrm{E}=$ Ethmoid, $\mathrm{F}=$ Frontal, $\mathrm{A}=$ Anterior $\mathrm{P}=$ Posterior

patients who had a failed surgical repair at our institution. The remaining 3 patients underwent a successful revision surgery by the senior author using a three layered closure technique and subsequent adaption of this approach for the recalcitrant cases in 2004. Since then, there have been no further failures after first attempt at our institution. All 4 patients had skull base defects of $\geq 4 \mathrm{~mm}$ and underwent our first surgical attempt in repair of CSF fistula prior to 2004 when we utilised a two layered repair technique (Table 2).

One patient successfully underwent her first endoscopic CSF fistula closure in conjunction with the insertion of a ventriculoperitoneal shunt as a combined case with the neurosurgeons. Another patient in our series had multiple defects (Table 2). Mean follow-up was 22.5 months with $95 \% \mathrm{Cl}(14.6-28.5$ months) and median of 19 months.

\section{Complications}

Other complications included three post-operative episodes of transient pyrexia, 24 hours postoperatively with negative blood cultures or evidence of meningitis. In addition two patients complained of hyposmia, two had persistent headaches requiring further management by neurologists and two developed intranasal synechiae, one of which required surgical division.

\section{Discussion}

This study outlines the management of one of the largest series of spontaneous CSF leaks over an 8 year period and compares well with the literature (Table 1) ${ }^{(2,6,9,11)}$.

The tendency of our patients to be obese, middle aged females corresponds with the documented overlapping demographic of spontaneous CSF rhinorrhoea and IIH ${ }^{(6,9,11,15)}$. A formal neurological review was performed for all patients pre-operatively for assessment and management of the underlying primary pathology leading to CSF rhinorrhoea ${ }^{(23)}$. If clinically indicated, a measurement of lumbar puncture opening pressures was carried out. Mean duration of CSF leak was 14.5 months prior to their presentation with a $22 \%$ risk of meningitis, similar to the literature ${ }^{(7)}$.

Idiopathic intracranial hypertension is not a well understood disease entity with hypotheses ranging from abnormalities in vitamin A metabolism, adipose tissue acting as an actively secreting endocrine tissue and cerebral venous anomalies (24). Equally, the management of these patients lacks a clear evidence base ${ }^{(24)}$. Whatever the cause, higher pressures lead to erosion of the skullbase with a predilection for the thinnest areas, namely the cribriform plate and sphenoid lateral pterygoid recess ${ }^{(2)}$. Exces- 
Table 2. Revision and notable cases.

\begin{tabular}{|c|c|c|c|c|c|c|c|}
\hline $\begin{array}{l}\text { Age } \\
\text { Sex }\end{array}$ & $\begin{array}{c}\text { BMI } \\
\left(\mathrm{Kg} / \mathrm{m}^{2}\right)\end{array}$ & $\begin{array}{l}\text { Site } \\
\text { Size }\end{array}$ & $\begin{array}{l}\text { Previous } \\
\text { surgery at } \\
\text { other unit }\end{array}$ & $\begin{array}{l}\text { Outcome after 1st } \\
\text { surgery }\end{array}$ & $\begin{array}{l}\text { Outcome after } \\
\text { 2nd surgery }\end{array}$ & Co-morbidities & $\begin{array}{l}\text { Follow up } \\
\text { (months) }\end{array}$ \\
\hline $65 \mathrm{~F}$ & 27.5 & Ethmoid $4 \mathrm{~mm}$ & No & Fail & Success & Hypertension & 24 \\
\hline $40 \mathrm{~F}$ & 37.1 & Sphenoid $5 \mathrm{~mm}$ & No & Fail & Success & $\begin{array}{l}\text { Hypertension, } \\
\text { Raised BMI }\end{array}$ & 96 \\
\hline $48 \mathrm{~F}$ & 34.0 & Sphenoid $13 \mathrm{~mm}$ & No & Fail & Success & Raised BMI & 32 \\
\hline $41 \mathrm{~F}$ & 43.6 & Fronto-ethmoidal $10 \mathrm{~mm}$ & 2 & Fail & $\begin{array}{l}\text { N/A Underwent } \\
\text { gastric banding } \\
\text { and weight loss }\end{array}$ & $\begin{array}{l}\text { Hypertension, } \\
\text { Raised BMI, } \\
\text { Type } 2 \text { Diabetes, } \\
\text { IIH }\end{array}$ & 36 \\
\hline $40 \mathrm{~F}$ & 38.9 & Sphenoid $12-15 \mathrm{~mm}$ & 2 & $\begin{array}{c}\text { Success } \\
\text { (Endoscopic closure } \\
\text { and ventriculo-perito- } \\
\text { neal shunt) }\end{array}$ & $\mathrm{N} / \mathrm{A}$ & $\begin{array}{c}\text { Raised BMI, } \\
\text { Type } 2 \text { Diabetes, } \\
\text { IIH }\end{array}$ & 18 \\
\hline $60 \mathrm{M}$ & 32.4 & Frontal $1.3 \mathrm{~mm} 2.4 \mathrm{~mm}$ & No & $\begin{array}{c}\text { Success } \\
\text { (Fronto-ethmoidal) }\end{array}$ & $\begin{array}{c}\text { Success } \\
\text { (Novel site, } \\
\text { lateral recess) }\end{array}$ & Raised BMI & 60 \\
\hline
\end{tabular}

$\mathrm{M}=$ Male; $\mathrm{F}=$ Female; $\mathrm{BMI}=$ Body mass index $; \mathrm{IIH}=$ Idiopathic intracranial hypertension

sive sinus cavity pneumatisation is also well recognised in those with spontaneous CSF leaks, which is also associated with thinning of the skull base ${ }^{(2)}$.

The anatomical locations in which the defects were found corresponded well to a recent large case series, with the commonest site being the cribriform plate ${ }^{(2)}$. It has been suggested that the cribriform plate's multiple perforations for the olfactory nerve fibres make it more susceptible to CSF leak formation ${ }^{(2)}$. This is corroborated by a recent paper indicating that a substantial pathway of CSF drainage into the lymphatic system occurs at the cribriform plate ${ }^{\left({ }^{8}\right)}$. In one patient in our series, the leak emanated from an extra foramen from the cribriform plate. A contemporary systematic review, however, indicates that the commonest fistula sites are ethmoid and sphenoid ${ }^{(16)}$.

Pre-operative work up in this series fits well with described management algorithms ${ }^{(25)}$. Nasal secretion test yielded positive for $\beta 2$ transferrin in $92 \%$ correlating with those in the literature ${ }^{(18)}$.

In keeping with accepted management algorithms, CT scans with $1 \mathrm{~mm}$ slices employing BrainLab ${ }^{\oplus}$ protocol (BrainLab AG, Heimstetten, Germany) were sufficient at delineating anatomical defects ${ }^{(25)}$. Magnetic resonance imaging proved to have a valuable complementary role, particularly in the presence of encephalocoeles ${ }^{(25)}$. From our experience, the above modalities proved to be sufficient except in cases with small defects of below $1 \mathrm{~mm}$ which were identified intra-operatively using intrathecal fluorescein. CT cisternography has been suggested by others as an adjunct but we have not found it necessary in our practice ${ }^{(25,26)}$.

Intraoperative intrathecal fluorescein was used in the majority of cases (92\%). This was higher than that described at other centres ${ }^{(18,27)}$. This was used in all revision cases, in those with potential multiple leak sites and in cases where imaging did not clarify an anatomical defect. No adverse reactions were reported to the intrathecal fluorescein, highlighting the efficacy and safety of fluorescein. A systematic review by Psaltis et al., also confirms its widespread use and safety profile when used in low concentrations such as those used in our series ${ }^{(25,26)}$.

A range of grafts, including fascia lata, Duragen ${ }^{\circledast}$ (Integra ${ }^{\mathrm{TM}}{ }^{\mathrm{M}}$ ), temporalis fascia, septal cartilage, bone pate were harvested from the mastoid, turbinate mucosa and fat ${ }^{(21)}$. Success rates for a variety of grafts are reported to be similar ${ }^{(28)}$. In large skull base defects, the use of vascularized tissue grafts has been correlated with lower failure rates but we did not require their $u^{2} e^{(29)}$. In our unit, grafts were chosen depending on the size and site of a leak. The use of a two layered repair was superseded by an anatomic three layered technique for defects $\geq 4 \mathrm{~mm}$ in 2004, replacing dura by fascia lata, bone by cartilage or bone pate and mucosa by mucosa ${ }^{(17)}$. This has been successful with 
no failures since its adoption ${ }^{(17)}$. Despite limitations associated with retrospective studies, we recommend a three layered technique for recalcitrant cases particularly given that a recent systematic review failed to identify an ideal method or materials for repair ${ }^{(16)}$. This review also revealed that a lumbar drain was utilised in half the cases ${ }^{(16)}$. Lumbar drain use remains a controversial topic, with no clear consensus in the literature and high success rates having being reported without their use ${ }^{(30,31)}$. In our series, lumbar drains were inserted in consultation with neurologists and included those with raised intracranial pressure, all revision cases and those with defects $\geq 4 \mathrm{~mm}$ in size. CSF pressure measurement was not regularly performed and was dependent on the clinical diagnosis of IIH by a dedicated neurologist. Although a routine pre-operative measurement of CSF pressure could have been useful in the assessment of the role of a lumbar drain, a recent study suggests that a single preoperative CSF pressure measurements in patients with active leaks are not sufficiently reliable to lead clinical decisions ${ }^{(32)}$. All sites of leaks were accessed endoscopically including two cases with frontal recess defects that were repaired with an endoscopic modified Lothrop/Draf III approach ${ }^{(19)}$.

There is no agreement on the use of prophylactic antibiotics post-operatively and reports indicate that the risk of meningitis is not reduced ${ }^{(33,34)}$. However, some authors recommend a minimum of 48 hours antibiotics whilst others treat subgroups with previous meningitis or revision cases ${ }^{(26,35)}$. We prescribed a one week course of antibiotics to reduce the risk of local infection due to nasal packing ${ }^{(36)}$.

Spontaneous CSF leaks are more difficult to manage compared to other aetiologies and hence have lower success rates ${ }^{(2,6)}$. This patient group is typically obese, middle aged women with defects in pneumatised sphenoid lateral recesses ${ }^{(2,6,15)}$. Elevated BMI and large skull base defects are associated with surgical failure in our series which corresponds to the literature ${ }^{(11)}$. Out of our 4 failure cases (Table 2), one CSF leak case in a 41 year old female with a BMI of $43.6 \mathrm{~kg} / \mathrm{m}^{2}$, demonstrated cessation following laparoscopic gastric bypass surgery and resultant significant weight loss, highlighting that bariatric surgery is a useful adjunct in the management of CSF rhinorrhoea. This concurs with the available evidence that bariatric surgery improves idiopathic intracranial hypertension and has the potential to aid management of CSF rhinorrhoea ${ }^{(5,37)}$.

Another notable case of a 40 year old female with confirmed IIH and raised BMI (Table 2) had failed both medical therapy with acetazolamide and two surgical repair attempts. We performed synchronised endoscopic repair of her CSF fistula and a ventriculo-peritoneal shunt insertion, resulting in resolution of her CSF leak. Ventriculo-peritoneal shunting is an effective and increasingly widespread treatment for idiopathic intracranial hypertension $(2,15,38)$. Therefore it may have contributed towards the success of our repair.

Endoscopic spontaneous CSF leak repair is the gold standard management and can be provided by an ENT surgeon with an interest in skull base surgery ${ }^{(6,9,11,15)}$. However, assessment of the underlying primary pathology and instigation of adjuvant therapies to address associated risk factors requires a multidisciplinary approach ${ }^{(2,6,15)}$. The positive impact of the gastric bypass surgery and possibly VP shunting in our series, highlight the importance of dealing with the primary underlying pathology. Adjuvant treatment modalities include conservative (diet and weight loss), medical (loop diuretics and carbonic anhydrase inhibitors such as furosemide and acetazolamide), radiological (intracranial venous shunting) and surgical (ventriculo-peritoneal shunting or bariatric surgery) options ${ }^{(2,5,6,15,37-41)}$. Further research is required to elucidate if, when and which treatments to employ ${ }^{(24)}$.

\section{Conclusion}

Endoscopic repair of spontaneous CSF rhinorrhoea is a safe and effective operation and has become the gold standard for management. We recommend a multidisciplinary approach to treat the primary underlying pathology of spontaneous CSF rhinorrhoea and utilisation of an anatomic three-layered closure in recalcitrant cases.

\section{Acknowledgement}

Nil to declare

\section{Authorship contribution}

All authors had full access to all data in the study and take responsibility for the integrity of the data and accuracy of data analysis. JV was the primary author, data collator and analyser of the manuscript alongside BE. CS collated aided in data collection and editing. HS was the senior clinician and contributed to the study concept, design and proof reading.

\section{Conflict of interest}

Nil to declare

\section{References}

1. Har-El G. What is "spontaneous" cerebrospinal fluid rhinorrhea? Classification of cerebrospinal fluid leaks. Ann Otol Rhinol Laryngol. 1999; 108: 323-326.

2. Seth R, Rajasekaran K, 3rd, Luong A,
Benninger MS, Batra PS. Spontaneous CSF leaks: factors predictive of additional interventions. Laryngoscope. 2010; 120: 2141 2146.

3. Dunn CJ, Alaani A, Johnson AP. Study on spontaneous cerebrospinal fluid rhinor- rhoea: its aetiology and management. J Laryngol Otol. 2005; 119: 12-15.

4. Jindal M, Hiam L, Raman A, Rejali D. Idiopathic intracranial hypertension in otolaryngology. Eur Arch Otorhinolaryngol. 2009; 266: 803-806 
5. Stangherlin $P$, Ledeghen $S$, Scordidis $V_{\text {, }}$ Rubay R. Benign intracranial hypertension with recurrent spontaneous cerebrospina fluid rhinorrhoea treated by laparoscopic gastric banding. Acta Chir Belg. 2008; 108: 616-618.

6. Wang EW, Vandergrift WA, 3rd, Schlosser RJ Spontaneous CSF Leaks. Otolaryngol Clin North Am. 2011; 44: 845-856, vii.

7. Daudia A, Biswas D, Jones NS. Risk of meningitis with cerebrospinal fluid rhinorrhea. Ann Otol Rhinol Laryngol. 2007; 116: $902-$ 905.

8. Sakka L, Coll G, Chazal J. Anatomy and physiology of cerebrospinal fluid. Eur Ann Otorhinolaryngol Head Neck Dis. 2011; 128: 309-316.

9. Banks CA, Palmer JN, Chiu AG, O'Malley BW, Jr., Woodworth BA, Kennedy DW. Endoscopic closure of CSF rhinorrhea: 193 cases over 21 years. Otolaryngol Head Neck Surg. 2009; 140: 826-833.

10. Cui S, Han D, Zhou Bet al. Endoscopic endonasal surgery for recurrent cerebrospinal fluid rhinorrhea. Acta Otolaryngol. 2010; 130: 1169-1174.

11. Lindstrom DR, Toohill RJ, Loehrl TA, Smith TL. Management of cerebrospinal fluid rhinorrhea: the Medical College of Wisconsin experience. Laryngoscope. 2004; 114: 969974.

12. Hubbard JL, McDonald TJ, Pearson BW, Laws ER, Jr. Spontaneous cerebrospinal fluid rhinorrhea: evolving concepts in diagnosis and surgical management based on the Mayo Clinic experience from 1970 through 1981. Neurosurgery. 1985; 16: 314-321.

13. Lopatin AS, Kapitanov DN, Potapov AA. Endonasal endoscopic repair of spontaneous cerebrospinal fluid leaks. Arch Otolaryngol Head Neck Surg. 2003; 129:859863.

14. Ommaya AK, Di Chiro G, Baldwin M, Pennybacker JB. Non-traumatic cerebrospinal fluid rhinorrhoea. J Neurol Neurosurg Psychiatry 1968; 31: 214-225.

15. Woodworth BA, Prince A, Chiu AG et al. Spontaneous CSF leaks: a paradigm for definitive repair and management of intracranial hypertension. Otolaryngol Head Neck Surg. 2008; 138: 715-720.

16. Psaltis AJ, Schlosser RJ, Banks CA, Yawn J, Soler ZM. A systematic review of the endoscopic repair of cerebrospinal fluid leaks. Otolaryngol Head Neck Surg. 2012; 147: 196-203.

17. Virk JS, Elmiyeh B, Saleh A. Endoscopic management of cerebrospinal fluid rhinorrhoea: the Charing Cross experience. J Neurol Surg .B 2013; in press

18. Lund VJ. Endoscopic management of cerebrospinal fluid leaks. Am J Rhinol. 2002 16: 17-23.

19. Anverali JK, Hassaan AA, Saleh HA. Endoscopic modified Lothrop procedure for repair of lateral frontal sinus cerebrospinal fluid leak. J Laryngol Otol. 2009; 123:
145-147.

20. Vaezi A, Snyderman $C H$, Saleh HA Carrau RL, Zanation A, Gardner P. Pseudomeningoceles of the sphenoid sinus masquerading as sinus pathology. Laryngoscope. 2011; 121: 2507-2513.

21. Chatrath P, Saleh HA. Endoscopic repair of cerebrospinal fluid rhinorrhea using bone pate. Laryngoscope. 2006; 116: 1050-1053.

22. Kassam A, Horowitz M, Carrau R, et al. Use of Tisseel fibrin sealant in neurosurgical procedures: incidence of cerebrospinal fluid leaks and cost-benefit analysis in a retrospective study. Neurosurgery. 2003; 52: 1102-1105.

23. Wall M. Idiopathic intracranial hypertension (pseudotumor cerebri). Curr Neurol Neurosci Rep. 2008; 8: 87-93.

24. Biousse V, Bruce BB, Newman NJ. Update on the pathophysiology and management of idiopathic intracranial hypertension. J Neurol Neurosurg Psychiatry. 2012; 83: 488494.

25. Lund VJ, Savy L, Lloyd G, Howard D. Optimum imaging and diagnosis of cerebrospinal fluid rhinorrhoea. J Laryngol Otol. 2000; 114: 988-992.

26. Gilat H, Rappaport Z, Yaniv E. Endoscopic transnasal cerebrospinal fluid leak repair: a 10 year experience. Isr Med Assoc J. 2011; 13: 597-600.

27. Seth R, Rajasekaran K, Benninger MS, Batra PS. The utility of intrathecal fluorescein in cerebrospinal fluid leak repair. Otolaryngol Head Neck Surg. 2010; 143: 626-632

28. Prickett KK, Wise SK, Delgaudio JM. Choice of graft material and postoperative healing in endoscopic repair of cerebrospinal fluid leak. Arch Otolaryngol Head Neck Surg 2011; 137: 457-461.

29. Harvey RJ, Parmar P, Sacks R, Zanation AM Endoscopic skull base reconstruction of large dural defects: a systematic review of published evidence. Laryngoscope 2012; 122: 452-459.

30. Casiano RR, Jassir D. Endoscopic cerebrospinal fluid rhinorrhea repair: is a lumbar drain necessary? Otolaryngol Head Neck Surg. 1999; 121: 745-750.

31. Caballero N, Bhalla V, Stankiewicz JA, Welch KC. Effect of lumbar drain placement on recurrence of cerebrospinal rhinorrhea after endoscopic repair. Int Forum Allergy Rhinol. 2012; 2: 222-6.

32. Ramakrishnan VR, Suh JD, Chiu AG, Palmer $\mathrm{JN}$. Reliability of preoperative assessment of cerebrospinal fluid pressure in the management of spontaneous cerebrospinal fluid leaks and encephaloceles. Int Forum Allergy Rhinol. 2011; 1: 201-205.

33. Kassam A, Carrau RL, Snyderman $\mathrm{CH}$ Gardner P, Mintz A. Evolution of reconstructive techniques following endoscopic expanded endonasal approaches. Neurosurg Focus. 2005; 19: E8.

34. Eljamel MS. Antibiotic prophylaxis in unrepaired CSF fistulae. Br J Neurosurg. 1993; 7: 501-505.
35. Carrau RL, Snyderman C, Janecka IP, Sekhar L, Sen C, D'Amico F. Antibiotic prophylaxis in cranial base surgery. Head Neck. 1991; 13: 311-317.

36. Shikani AH. Use of antibiotics for expansion of the Merocel packing following endoscopic sinus surgery. Ear Nose Throat J. 1996; 75: 524-526, 528

37. Fridley J, Foroozan R, Sherman V, Brandt ML, Yoshor D. Bariatric surgery for the treatment of idiopathic intracranial hypertension. J Neurosurg. 2011; 114: 34-39.

38. Curry WT, Jr., Butler WE, Barker FG, 2nd. Rapidly rising incidence of cerebrospinal fluid shunting procedures for idiopathic intracranial hypertension in the United States, 1988-2002. Neurosurgery. 2005; 57: 97-108.

39. Kumpe DA, Bennett JL, Seinfeld J, Pelak VS, Chawla A, Tierney M. Dural sinus stent placement for idiopathic intracranial hypertension. J Neurosurg. 2012; 116: 538-548.

40. Kahle KT, Walcott BP, Staley KJ. Resolution of headache and papilledema in idiopathic intracranial hypertension associated with inhibition of $\mathrm{Na}+-\mathrm{K}+-2 \mathrm{Cl}$ - cotransport. J Child Neurol. 2011; 26: 205-208.

41. Ball AK, Howman A, Wheatley Ket al. A randomised controlled trial of treatment for idiopathic intracranial hypertension. J Neurol. 2011; 258: 874-881

42. Schlosser RJ, Wilensky EM, Grady MS, Bolger WE. Elevated intracranial pressures in spontaneous cerebrospinal fluid leaks. Am J Rhinol. 2003; 17: 191-195.

43. Mains KC, Gross CW, Kountakis SE. Endoscopic management of cerebrospinal fluid rhinorrhea. Laryngoscope. 2004; 114: 1833-1837.

44. Mirza S, Thaper A, McClelland L, Jones NS. Sinonasal cerebrospinal fluid leaks: management of 97 patients over 10 years. Laryngoscope. 2005; 115: 1774-1777.

45. Presutti L, Mattioli F, Villari D, Marchioni D, Alicandri-Ciufelli M. Transnasal endoscopic treatment of cerebrospinal fluid leak: 17 years' experience. Acta Otorhinolaryngol Ital. 2009; 29: 191-196.

46. Cassano M, Felippu A. Endoscopic treatment of cerebrospinal fluid leaks with the use of lower turbinate grafts: a retrospective review of 125 cases. Rhinology. 2009; 47: 362-368.

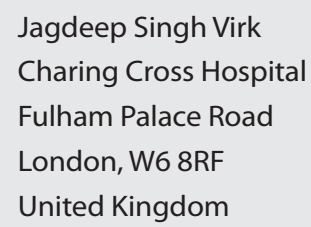

Tel: +44-(0)790-8960034

Fax: +44-(0)208-869 3098

Email:j_v1rk@hotmail.com 